\title{
PENGARUH PEMBELAJARAN KASTI MODIFIKAASI TERHADAP NILAI KERJASAMA PADA SISWA SEKOLAH DASAR
}

\author{
Muhamad Ade Jaenudin ${ }^{1}$, Adang Suherman ${ }^{2}$, Komarudin $^{3}$
}

Universitas Pendidikan Indonesia, Bandung

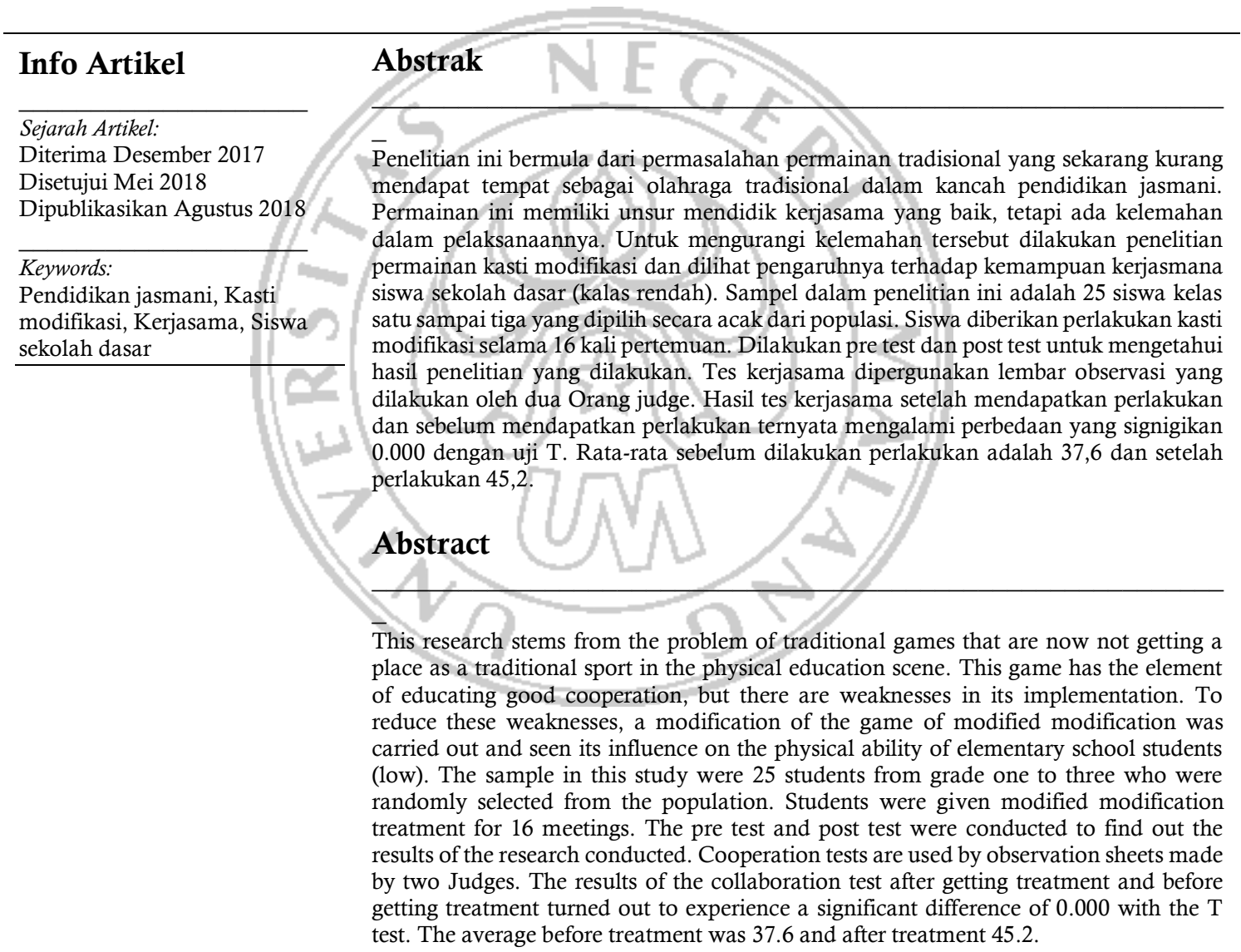

(C) 2018 Universitas Negeri Malang

$凶$ Alamat korespondensi:

ISSN 2614-8293 (Online)

E-mail: muhamadadejaenudin@gmail.com 


\section{PENDAHULUAN}

Pendidikan jasmani diajarkan di semua jenjang pendidikan dan memberikan kontribusi pada prestasi akademis siswa khususnya di bidang bahasa, membaca, dan matematika, khususnya ketika diajarkan oleh guru yang terlatih baik dalam pedagogis maupun permainan atau olahraga (Sallis et al. 1999). Hal ini bukan saja berlaku pada pelajar sekolah dasar tetapi juga sekolah menengah (Booth et al. 2013). Pendidikan jasmani juga mampu memberikan kontribusi terhadap kebugaran dan aktivitas jasmani pelajar (Sallis et al. 1997).

Sehubungan dengan itu, pendidikan jasmani di sekolah dasar mempunyai peranan yang sangat penting karena pendidikan jasmani merupakan upaya pendidikan yang langsung memberi dampak terhadap pertumbuhan dan perkembangan fisik serta psikis anak-anak didik. Pendidikan jasmani pada umumnya mempergunakan aktivitas jasmani dengan permainan yang mengembangkan kemampuankemampuan yang bersifat jasmani koordinasi gerak kejiwaan dan sosial. Selain itu, pendidikan jasmani juga dapat membina karakter dan nilainilai (Suherman et al. 2017; Suherman 2015).

Sementara itu menurut Wuest \& Bucher (2003), nilai yang dapat diajarkan dalam pendidikan jasmani mencakup nilai kerjasama, disiplin diri, permainan yang adil (fair-play), pengendalian emosional, kerja kelompok, kepercayaan diri, dan keyakinan diri. Beberapa pendapat tersebut menunjukkan bahwa nilai yang dapat ditransfer melalui pendidikan jasmani sangat kompleks mulai dari kecerdasan emosional, kerjasama, disiplin, percaya diri, keyakinan diri, pengendalian emosi yang dapat diterapkan dalam kehidupan masyarakat. Nilainilai dapat dicapai dengan melalui proses penyelenggaraan pendidikan jasmani yang bermakna (Russell 2004).

Berdasarkan pemaparan di atas nilainilai tersebut dapat dikembangkan sejak proses perkembangan anak. Karena penanaman nilai harus dimulai sejak dini. Penanaman nilai akan lebih bermakna jika disampaikan tidak hanya dengan memberitahu secara verbal saja (Sultoni et al. 2017). Pendidikan jasmani dengan aktivitas jasmani yang dilakukan merupakan miniatur dari kehidupan sosial dalam masyarakat. Dalam kehidupan salah satunya diperlukan kerjasama agar tercipta kehidupan yang harmonis. Kerjasama untuk menjaga keamanan, kebersihan, toleransi, mendidik anak dalam tata budaya masyarakat.

Nilai kerjasama merupakan nilai yang sangat penting baik dalam pendidikan jasmani maupun dalam kehidupan sehari-hari, karena semua siswa tanpa melihat tingkat kemampuan, harus bertindak bersama agar menjadikan pelajaran bermanfaat bagi masing-masing individu (Svennberg et al. 2014). Oleh karena itu pendidikan jasmani lebih mengarah pada aspek sosiomotor ketimbang psikomotor (Jaqueira et al. 2012)

Permainan kasti memiliki potensi edukasi yang tinggi. Ada nilai kerjasama, kerja keras, menghargai teman dan lawan, komunikasi, percaya diri, sportif, kompetiti. Permainan ini dengan desain pembelajaran yang benar dapat dipergunakan sebagai alat untuk mendidik karakter siswa. Berkaitan dengan pendidikan karakter siswa tentunya harus dibentuk dalam peraturan yang harus ditepati, dan desain yang baik.

Pelaksanaan permainan kasti agar mencapai kemenangan dibutuhkan kepatuhan terhadap peraturan dan kerjasama agar permainan berjalan dengan sportif. Ketika siswa bergerak maka proses pematangan gerak dasar sedang berlangsung, ketika siswa berkomunikasi untuk mendapatkan poin atau mencegah poin adalah salah satu contoh bentuk kerjasama dalam kontek sosiosport yang dapat berlanjut pada keintiman diantara siswa setelah proses belajar mengajar dan menjadi bekal dalam kehidupannya kelak. Pesan karakter dalam pendidikan dapat tersempaikan bersamaan dengan permainan yang dilaksanakan, sesuai dengan rancangan pembelajaran yang disusun.

Selanjutnya dalam permainan kasti adalah nilai tradisional. Sebagai budaya lokal, permainan ini telah dimasukkan dalam kurikulum pendidikan secara nasional. Dengan dimasukkannya permainan ini dalam kurikulum dipastikan permainan ini telah ditelaah nilai 
positif yang terkandung di dalamnya. Upaya untuk melestarikan budaya lokal harus dilakukan sebagai ciri dari budaya bangsa. Jangan sampai generasi mendatang tidak mengetahui hasil dan keberadaan budaya sendiri. Sehingga upaya modifikasi dan pengaruhnya menjadi bahan penelitian yang menarik untuk dikaji. Maka dari itu, tujuan penelitian ini adalah untuk memeriksa efek modifikasi permainan dengan pertanyaan penelitian sebagai berikut: Apakah terdapat pengaruh yang signifikan pembelajaran kasti modifikasi terhadap kerjasama

\section{METODE}

Penelitian dilakukan dengan metode eksperimen dengan menggunakan sampel siswa sekolah rendah Sekolah Dasar Negeri Karyajaya berjumlah 25 siswa. Siswa mendapat perlakukan permainan kasti modifikasi selama 16 kali pertemuan dengan sebelumnya diberikan pretest bermain kasti yang diamati oleh judge. Setelah mendapat perlakukan 14 kali dilakukan post test kembali dengan dilakukan pengamatan bermain yang diobservasi pada bagian kerjasama oleh judge yang sama ketika melakukan pre-test. Data dianalisis dengan uji paired sample t-test, dengan taraf signifikansi 0.05

HASIL

Tabel 1. Descriptive statistics

\begin{tabular}{|l|l|c|c|c|c|}
\hline \multicolumn{2}{|c|}{} & N & Mean & Std. Deviation & Std. Error Mean \\
\hline \multirow{2}{*}{ Pair 1 } & Pre-test & 25 & 37.6800 & 2.59358 & .51872 \\
\cline { 2 - 6 } & Post-test & 25 & 45.2000 & 1.93649 & .38730 \\
\hline
\end{tabular}

Berdasarkan pada hasil analisis di atas, dilihat nilai rerata dapat diartikan bahwa hasil pre test berdasarkan perlakukan kasti modfifikasi ternyata dapat dilihat nilai rerata untuk pre test lebih kecil dibandingkan dengan nilai post test. Dilihat dari nilai rerata ini dapat disimpilkan bahwa nilai skor post test lebih tinggi, sehingga dapat dikatakan bahwa permainan kasti modifikasi hasil dari penelitian
Penelitian ini dilakukan dalam beberapa tahap penelitian dengan variabel penelitian kerjasama menggunakan kasti modifikasi. Penelitian tahap pertama bertujuan untuk mendapatkan format kasti modifikasi yang sesuai untuk siswa sekolah dasar kelas rendah. Berkaitan dengan hal tersebut dilakukan permaian kasti dengan uji validitas terhadap peraturan, perlengkapan, dan peralatan dengan krietria yang divalidasikan ke judge.

Penelitian ini dilaksanakan selama tiga bulan dengan melakukan eksperimen terhadap siswa sekolah dasar kelas satu, dua, dan tiga dengan sampel berjumlah 25 siswa. Perlakuan yang dilakukan dalam penelitian ini adalah pembelajaran permainan dengan modifikasi.

Penelitian berikutnya menggali informasi dan membuktikan secara ilmiah pengaruh pembelajaran kasti modifikasi terhadap kerjasama. Kemampuan kerjasama diukur dengan pengamatan berupa skala pengamatan yang terdiri dari enam indikator penilaian. Keenam indikator tersebut adalah penyesuaian, koordinasi, pengambilan keputusan, kepemimpinan, komunikasi dan interpersonal yang telah didefinisikan secara operasional dan selanjutnya disusun dengan lembar observasi sebagai variabel kerjasama. Hasil deskriptif statistic sebagai berikut:

Tabel 2. Paired samples t- test

\begin{tabular}{|l|c|c|c|c|c|c|}
\hline & \multicolumn{3}{|c|}{ Paired Differences } & t & df & Sig. (2-tailed) \\
\cline { 2 - 7 } & Mean & Std. Deviation & Std. Error Mean & & & \\
\hline Pre-test - post-test & -7.52000 & 2.55147 & .51029 & -14.737 & 24 & .000 \\
\hline
\end{tabular}

\section{PEMBAHASAN}

tahap pertama dengan uji ekspereimen ini menghasilkan peningkatan kerjasama siswa. Kerjasama yang dimaksud adalah dapat terlihat dalam keenam indikator kerjasama. Ketika dilakukan uji lanjut dengan menggunakan uji $\mathrm{T}$ berpasangan diperoleh nilai signifikansi sebagai berikut: 
ketentuan dengan baik sehingga dapat digunakan untuk siswa kelas rendah. Menurut Wibowo (2010) kerjasama berarti bekerja secara bersama-sama dalam mengerjakan sesuatu untuk suatu tujuan tertentu. Dengan kerjasama faktor yang mempengaruhi dalam bekerjasama yaitu kemampuan beradaptasi, kemampuan berkoordinasi, kemampuan komunikasi, kemampuan pengambilan keputusan, kemampuan memimpin, dan kemampuan individu bisa diterima siswa kelas rendah karena siswa dapat melakukannya dengan baik. Hal tersebut sesuai dengan pendapat Margono, Mukholid, Purnama, \& Satyawan (2013), bahwa pengembangan kerjasama dapat diajarkan dalam gerak dasar lari dalam bentuk lari saling menjemput teman dengan ban bekas atau simpai, lari sambil mengoper bola ke teman, atau lari sambil menyampaikan pesan bersambung.

Hal yang sama dibuktikan pada saat pelaksanaan pembelajaran modifikasi permainan tradisional kasti bahwa team bermain dengan cara memulai permainan diawali oleh pemukul yang memukul bola di atas cone (Tiang penyimpan bola), setelah memukul bola pemukul berlari ke tiang hinggap satu, pemukul ke dua memukul bola kemudian berlari ke tiang hinggap satu dan yang berada di tiang hinggap satu harus berlari ke tiang hinggap dua. Pemukul ke tiga memukul bola kemudian berlari ke tiang hinggap satu, yang berada di tiang hinggap dua harus berlari ke tiang hinggap tiga. Pemukul keempat setelah memukul bola berlari ke tiang hinggap satu, yang berada ditiang hinggap satu harus berlari ke tiang hinggap dua, yang berada di tiang hinggap dua harus berlari ke tiang hinggap tiga dan yang berada di tiang hinggap tiga harus berlari ke tiang hinggap empat. Pemukul kelima memukul bola setelah memukul bola harus berlari ke tiang hinggap satu, yang berada di tiang hinggap satu berlari ke tiang hinggap dua, yang berada di tiang hinggap dua harus berlari ke tiang hinggap tiga, yang berada di tiang hinggap tiga harus berlari ke tiang hinggap empat, yang berada di tiang hinggap empat harus berlari ke ruang bebas. Team penjaga siap mematikan team penyerang yang akan hinggap pada setiap tiang hinggap. Dengan kegiatan tersebut siswa dibiasakan bekerja sama dalam team sehingga siswa akan merasakan suasana pembelajaran yang menyenangkan, yang di dalamnya terdapat kesepakatan dengan kerjasama yang baik akan menghasilkan nilai yang baik. Dengan nilai yang baik siswa akan merasa senang karena salah satu hasil dari pembelajaran adalah nilai yang akan diterima siswa baik pada saat proses pembelajaran maupun setelah pembelajaran.

Berdasar pada pemaparan di atas modifikasi berhasil memudahkan siswa dalam menumbuhkan kerjasama pada siswa kelas rendah, karena kelas rendah merupakan siswa dengan usia antara tujuh sampai sembilan tahuan, jika dilihat dari segi usia masih belum mampu untuk megikuti pembelajaran dengan konvensional. Dengan adanya modifikasi siswa kelas rendah dapat melakukan permainan tradisional kasti tanpa menghilangkan esensi dari kasti itu sendiri dan guru dapat mencapai tujuan pembelajaran dengan optimal karena permainan kasti masuk ke dalam kurikulum sekolah dasar.

Berikut hasil penelitian Fontana (2007) dalam upaya untuk melihat kemampuan orang untuk melakukan pengambilan keputusan dilakukan penelitian ini. Dilihat bagaimana orang dapat mengambil keputusan dengan intensitas latihan $40 \%, 60 \%$, dan $80 \%$ terhadap pemain bola pemula 16 dan pengalaman 16 . Dalam penelitian dihasilkan baik orang pemula dan berpengalaman kecepatan dalam melakukan pengambilan keputusan sama-sama mengalami peningkatan seiring dengan naiknya intensitas latihan.

Kaitannya dengan hal ini bahwa dalam permainan dibutuhkan kemampuan untuk memutuskan apa yang harus dilakukan, kemana, dengan siapa dan dengan cara apa. Dalam konteks bermain siswa dipaksa untuk memutuskan sendiri dalam waktu yang sangat cepat ketika ingin mematikan lawan ataupun mendapat point. Bagi siswa pemula dalam bermain situasi ini tidak mudah, berdasarkan hasil penelitian dalam penelitian ini diketahui bahwa dengan menggunakan modifikasi hasilnya lebih baik. Hal ini dikarenakan keterlibatan yang lebih besar disebabkan adanya jumlah tiang/base yang lebih banyak dan kesempatan untuk bergerak menjadi lebih banyak.

Selanjutnya Hepler \& Feltz (2012) yang melakukan peneltian dengan tujuan menghubungkan antara keyakinan diri terhadap kemampuan dan kecepatan melakukan pengambilan keputusan dalam permainan baseball. Berdasarkan penelitian yang dilakukan diperoleh hasil yang signifikan, terbukti bawa keyakinan diri secara konsisten mempengarui dalam kinerja dalam melaksanakan keputusan.

Keterkaitan dalam penelitian ini adalah ketika siswa kelas rendah melaksanakan permainan, dimana permainan tersebut memerlukan pemikiran dan harus melakukan pengambilan keputusan, dalam hal ini 
diperlukan keyakinan diri yang menuntut kepercayaan diri untuk melaksanakan keputusan. Sehingga dengan setting pembelajaran bermain maka akan merangsang anak untuk dengan cepat merespon dan melaksanakan gerakan yang dianggap perlu berdasarkan pengalaman, pemahaman yang dimiliki oleh siswa.

Temuan penelitian ini ternyata didukung juga oleh penelitian-penelitian yang lain diantaranya The finding that self-efficacy was significantly and positively related to decision-making performance on a simulated sports task was not surprising, as previous research involving sports consistently supported this relationship Moritz, Quan, Rickhi, \& Liu (2006).

Penelitian lain yang mendukung perihal pengambilan keputusan adalah yang dilakukan oleh Gabbett, Carius, \& Mulvey (2008) bahwa dengan menggunakan video ternyata dapat dipergunakan untuk membantu atlet dalam belajar semakin mengefektifkan pengambilan keputusan. Hal ini akan memperkaya pada area peseptual learning. Siswa yang sedang belajar permainan baru ataupun permainan yang lama, jika merujuk pada penelitian ini maka diperlukan media video untuk meningkatkan kinerja dalam pembelajaran yang pada akhirnya akan meningkatkan kemampuan - untuk pengambilan keputusan dalam permainan. Dan ditekankan oleh peneliti bahwa dengan menggunakan video berdasarkan apa yang dilakukan sendiri akan lebih baik hasilnya.

\section{KESIMPULAN}

Hasil penelitian berdasarkan deskripsi data dan pengujian dengan menggunakan uji beda sampel berpasangan, dapat disimpulkan bahwa permainan kasti yang dimodifikasi dapat dipergunakan untuk meningkatkan nilai kerjasama. Kerjasma dimaksud adalah secara bersama sama (team) melakukan penyerangan dan pertahan untuk membuat skor ataupun mencegah terjadinya skor. Kegiatan penilaian kerjasmana dengan keenam indikator penilaian tersebut dapat menggambarkan bagaiman kerjsmama seara riil di lapangan.

\section{DAFTAR PUSTAKA}

Booth, J.N. et al., 2013. Associations between objectively measured physical activity and academic attainment in adolescents from a UK cohort. British Journal of Sports Medicine, p.bjsports-2013.

Fontana, F.E., 2007. The effects of exercise intensity on decision making performance of experienced and inexperienced soccer players, University of Pittsburgh.

Gabbett, T.J., Carius, J. \& Mulvey, M., 2008. Does improved decision-making ability reduce the physiological demands of game-based activities in field sport athletes? The Journal of Strength \& Conditioning Research, 22(6), pp.20272035.

Hepler, T.J. \& Feltz, D.L., 2012. Path analysis examining self-efficacy and decisionmaking performance on a simulated baseball task. Research quarterly for exercise and sport, 83(1), pp.55-64.

Jaqueira, A.R.F. et al., 2012. Observation of recreational routines in school break times. Revista Pedagógica ADAL, (24), pp.14-18.

Margono, A. et al., 2013. Modul pendidikan dan latihan profesi guru (PLPG) pendalaman materi penjas. Konsorsium sertifikasi guru (KSG). Modul PLPG_Pendidikan jasmani dan kesehatan. UNIMED.

Moritz, S. et al., 2006. A home study-based spirituality education program decreases emotional distress and increases quality of life-a randomized, controlled trial. Alternative therapies in health and medicine, 12(6), p.26.

Russell, D.A., 2004. Hoop frequency as a predictor of performance for softball bats. The Engineering of Sport, 5, pp.1-2.

Sallis, J.F. et al., 1999. Effects of health-related physical education on academic achievement: Project SPARK. Research quarterly for exercise and sport, 70(2), pp.127-134.

Sallis, J.F. et al., 1997. The effects of a 2-year physical education program (SPARK) on physical activity and fitness in elementary school students. Sports, Play and Active Recreation for Kids. American journal of public health, 87(8), pp.1328-1334.

Suherman, A., 2015. The Analysis Of Character Education In Teaching Physical Education. In International Conference on Innovation in Engineering and Vocational Education (ICIEVE). 
Suherman, A., Sultoni, K. \& Ilmawati, H., 2017. Character Based Physical Education Model. In IOP Conf. Series: Materials Science and Engineering. pp. 1-5. Available at: http://stacks.iop.org/1742$6596 / 755 / \mathrm{i}=1 / \mathrm{a}=011001$ ?key=crossref. 0 cdd0e5fffab2dd74a68d0f9f4f1296b.

Sultoni, K., Jajat \& Fitri, M., 2017. HealthRelated Fitness Knowledge and Its Relation to College Student Physical Activity. In IOP Conf. Series: Materials Science and Engineering. pp. 1-4. Available at: http://stacks.iop.org/1742$6596 / 755 / \mathrm{i}=1 / \mathrm{a}=011001$ ? $\mathrm{key}=$ crossref. 0 cdd0e5fffab2dd74a68d0f9f4f1296b.

Svennberg, L., Meckbach, J. \& Redelius, K., 2014. Exploring PE teachers' "gut feelings" An attempt to verbalise and discuss teachers' internalised grading criteria. European Physical Education Review, 20(2), pp.199-214.

Wibowo, Y.A., 2010. Bermain dan Kreativitas dalam Pembelajaran Pendidikan Jasmani. Jurnal Pendidikan Jasmani Indonesia, 7(2).

Wuest, D.A. \& Bucher, C.A., 2003. Foundations of physical education, exercise science, and sport, McGraw-Hill. 